\title{
Impact of the disease: acceptability, ceiling and floor effects and reliability of an instrument on heart failure
}

\author{
IMPACTO DA DOENÇA: ACEITABILIDADE, EFEITOS TETO E CHÃO E CONFIABILIDADE \\ DE UM INSTRUMENTO NA INSUFICIÊNCIA CARDÍACA
}

\author{
IMPACTO DE LA ENFERMEDAD: ACEPTABILIDAD, EFECTOS PICO Y TIERRA Y \\ CONFIABILIDAD DE UN INSTRUMENTO EN LA INSUFICIENCIA CARDIACA
}

\section{Simey de Lima Lopes Rodrigues ${ }^{1}$, Roberta Cunha Matheus Rodrigues ${ }^{2}$, Thaís Moreira São-João ${ }^{3}$, Renata Bigatti Bellizzotti Pavan, Kátia Melissa Padilha ${ }^{5}$, Maria-Cecília Gallani ${ }^{6}$}

\begin{abstract}
This study evaluated the acceptability, ceiling/floor effects, and the reliability of the instrument for measuring the Impact of the Disease on the Daily Life of Patients with Valvular Disease (IDCV) when applied to 135 patients with heart failure (HF). Acceptability was evaluated by the percentage of unanswered items and by the proportion of patients who responded to all items; the ceiling/floor effects by the percentage of patients who scored in the top of $10 \%$ best and worst results of the scale, respectively. Reliability was estimated by internal consistency (Cronbach's alpha coefficient) and stability of the measure (intraclass correlation coefficient - ICC). All patients responded to all items. Ceiling/floor effects evidenced were of moderate magnitude. The Cronbach's alpha was satisfactory for the majority of the domains and ICC $>0.90$ in all the domains. The IDCV proved to be an easy to understand questionnaire, with evidence of reliability in patients with HF.
\end{abstract}

\section{DESCRIPTORS}

Heart failure

Nursing care

Questionnaires

Validation studies

Reproducibility of results

\section{RESUMO}

Este estudo avaliou a aceitabilidade, os efeitos teto/chão e a confiabilidade do instrumento para mensuração do impacto da doença no cotidiano do valvopata (IDCV) quando aplicado a 135 pacientes com insuficiência cardíaca. A aceitabilidade foi avaliada pelo percentual de itens não respondidos e pela proporção de pacientes que responderam a todos os itens; os efeitos teto/chão pela percentagem de pacientes que pontuaram nos $10 \%$ melhores e nos piores resultados da escala, respectivamente. A confiabilidade foi estimada por meio da consistência interna (coeficiente alfa de Cronbach) e da estabilidade da medida (coeficiente de correlação intraclasse - ICC). Todos os pacientes responderam a todos os itens. Foram evidenciados efeitos teto/chão de moderada magnitude. Constatou-se alfa de Cronbach satisfatório para a maioria dos domínios e ICC > 0,90 em todos os domínios. O IDCV demonstrou ser um questionário de fácil compreensão, com evidências de confiabilidade em pacientes com IC.

\author{
DESCRITORES \\ Insuficiência cardíaca \\ Cuidados de enfermagem \\ Questionários \\ Estudos de validação \\ Reprodutibilidade dos testes
}

\begin{abstract}
RESUMEN
Este estudio evaluó la aceptabilidad, los efectos pico/tierra y la confiabilidad del instrumento para medir el impacto de la enfermedad en la vida diaria de pacientes con valvulopatía - (IDCV) aplicado a 135 pacientes con insuficiencia cardíaca. La aceptabilidad fue evaluada por el porcentaje de ítems no respondidos y por la proporción de pacientes que respondieron a todas los ítems; los efectos pico/tierra se calcularon como el porcentaje de pacientes que marcaron en los $10 \%$ mejores y en los peores resultados de la escala, respectivamente. La confiabilidad fue estimada por medio de la consistencia interna (coeficiente alfa de Cronbach) y de la estabilidad de la medida (coeficiente de correlación intra-clase-CCl). Todos los pacientes respondieron a todos los ítems. Se evidenció efectos pico/tierra de moderada magnitud. Se constató alfa de Cronbach satisfactorio para la mayoría de los dominios y $\mathrm{CCl}>0,90$ en todos los dominios. El IDCV demostró ser un cuestionario de fácil comprensión, con evidencias de confiabilidad en pacientes con IC.
\end{abstract}

\author{
DESCRIPTORES \\ Insuficiencia cardíaca \\ Atención de enfermería \\ Cuestionarios \\ Estudios de validación \\ Reproducibilidad de resultados
}

\footnotetext{
${ }^{1}$ Nurse. MSc, Post Graduate Program in Nursing, Faculty of Nursing, University of Campinas. Campinas, SP, Brazil. simey.lima@gmail.com ${ }^{2}$ Nurse. PhD, Associate Professor, Faculty of Nursing, University of Campinas. Campinas, SP, Brazil. robertar@fcm.unicamp.br ${ }^{3}$ Nurse. Post-Doctorate Fellow Faculty of Nursing, University of Campinas. Campinas, SP, Brazil. thaisms@gmail.com ${ }^{4}$ Nurse. MSc, Graduate Program in Nursing, Faculty of Nursing, University of Campinas. Campinas, SP, Brazil. rebigatti@yahoo.com.br ${ }^{5}$ Nurse. PhD, Post Graduate Program in Nursing, Faculty of Nursing, University of Campinas. Campinas, SP, Brazil. kapadilha@yahoo.com.br ${ }^{6}$ Nurse. PhD, Titulaire Professor, Faculté des sciences infirmières - Université Laval. Chercheure - Centre de Recherche de l'Institut universitaire de cardiologie et de pneumologie de Québec. Québec, QC, Canada. maria-cecilia.gallani@fsi.ulaval.ca
} 


\section{INTRODUCTION}

Heart failure (HF) represents remarkable rates of hospitalization and morbidity-mortality. In the United States, HF affects $2.4 \%$ of the adult population and over $11 \%$ of the population aged over 80 years. In 2015, it is estimated that the cost of HF in the U.S.A. will total 44.6 billion dollars ${ }^{(1)}$.

Symptoms and clinical signs observed in HF create significant repercussions on peoples' daily lives, especially in the physical and psychosocial spheres. In the physical aspect, dyspnea and fatigue stand out aCrawformong the most frequent and distressing for the patient ${ }^{(2-3)}$. Anxiety, depression and loss of self-control are reported among the psychosocial aspects ${ }^{(4)}$.

The daily perceived impact of HF influences the patient's adaptation to this condition ${ }^{(5)}$ and interferes with adherence to pharmacological and nonpharmacological treatment $^{(6)}$, both of which are essential for the control of disease progression and to optimize Health Related Quality of Life $(\mathrm{HRQOL})^{(7)}$.

The impact of the disease can be measured through functional capacity, evaluation of organic systems and the economic and epidemiologic impact of the disease ${ }^{(8)}$, as well as the measurement of the individual's perception about how the disease has affected his life in the social, physical, emotional and spiritual aspects ${ }^{(9)}$.

In the dimension of the individual's perception about how the disease influenced his life, beliefs are emphasized, in that the evaluation that the person makes about the impact of the disease depends on the beliefs that are constructed in this respect due to his experiences, the environment in which he lives, and his personality ${ }^{(9)}$.

In the literature, studies are found ad-
Although Instrument for Measuring the Impact of Disease in the Daily Life of Valvular Disease Patients was developed to evaluate the impact of valvular pathology, the refinement of its items resulted in the selection of issues relevant to the assessment of the impact not only of valvular disease, but among subjects with cardiac disorders with similar symptoms.
Considering the properties of satisfactory measures obtained with the application of IDCV in valvular pathologies, coronary artery and hypertensive diseases, as well as the similarity of the repercussions of HF on the life of the subject, it was hypothesized that the IDCV would be relevant for assessing the impact of the disease on the daily life of the patient with HF.

Thus, this study aimed to verify the acceptability, the ceiling and floor effects, and the reliability of IDCV when applied to outpatients with HF.

\section{METHOD}

\section{Design}

This was a methodological study, which investigated the methods for obtaining, organizing and analyzing data, destined for the development, validation and evaluation of instruments and research techniques ${ }^{(12)}$.

\section{Settings}

The study was developed in an outpatient clinic, specialized in cardiology, of a public teaching hospital located in the state of São Paulo.

$\mathrm{HF}$ interferes in $\mathrm{HRQoL}$, based on the assumption th the greater the perception of negative impact of the disease, the worse the HRQoL ${ }^{(4)}$. However, few studies are proposed to measure the impact of the disease in a more profound way, taking into consideration the beliefs of the subject in relation to morbidity and treatment. The understanding of the patient's perception about his health condition is essential to design interventions that can assist him in coping with the disease process.

In order to assess the individual's perception regarding the impact of the disease on his daily life, based on the subject's beliefs about the disease and treatment, an instrument was constructed to measure the impact

\section{Sample}

The sample consisted of 135 patients, aged 18 years or older, diagnosed with HF, who were followed up at that service for at least six months. Those subjects with the inability for effective verbal communication, those who underwent heart transplantation, and / or those diagnosed with oncological diseases were excluded.

\section{Sample Size Calculation}

The sample size was determined based on the Spearman correlation coefficient between the IDCV, the Minnesota 
Living with Heart Failure Questionnaire (MLHFQ) and the Medical Outcomes Study 36-item Short-Form Health Survey (SF-36) $(r=0.70)$ instruments, with an alpha $=0.05$ and $\beta=$ 0.10 . Considering the accuracy of the estimate of the intraclass correlation coefficient (ICC) of 0.70 , with a margin of error of 0.10 and an alpha of $0.05(13)$, it was estimated that $n=$ 89 subjects would be needed for the retest.

\section{Data collection}

The data were collected by the main researcher, after obtaining the signature on the Informed Consent (IC), individually, in a private environment, during the period from December of 2010 up to March of 2012, according to these steps:

- First step: at the baseline, sociodemographic and clinical data were gathered by consulting the medical chart, followed by structured interview technique for the evaluation of the impact of the disease through the application of the IDCV (test);

- Second step: performed seven (7) to twenty-one (21) days after the first step, with the application of the IDCV (retest) among 89 individuals who responded to the IDCV test.

\section{Instruments}

\section{Sociodemographic and clinical instrument}

This was a validated instrument ${ }^{(2)}$ divided into items: Sociodemographic characterization - age, registration number on the medical chart, gender, education, marital status, employment, social life and family income, and Clinical Characterization - functional classification (FC) of the heart failure according to the New York Heart Association $^{(14)}$, symptoms in the month prior to the interview (dyspnea, fatigue, chest pain, palpitations, syncope and edema of the lower limbs) and comorbidities - hypertension, diabetes mellitus (DM), dyslipidemia, renal failure, stroke, and lifestyle habits (smoking and/or drinking). Data from the echo Doppler cardiography - left ventricular ejection fraction (LVEF), systolic dysfunction (presence of one and / or more changes: akinesia, hypokinesia, dyskinesia or lowered LVEF) and diastolic dysfunction (obtained through the medical chart) were investigated.

\section{Instrument for measuring the Impact of Disease in the Daily Life of Valvular Disease Patients (IDCV)}

The instrument was composed by two scales ( $A$ and $B$ ). The part $A$ consisted of items that evaluated the impact, and the part $B$, of items that assessed each of the consequences listed in part A, totaling 14 items.

The items were grouped into four factors or domains: Physical impact of the disease - symptoms (items 11, 12 and 13); Impact of the disease on daily activities (items 5,7, 9, 10 and 14); Social and emotional impact of the disease (items 2, 3, 4 and 6) and Adaptation to the disease (items 1 and 8).
In the first scale (Part A), the answers ranged, in a fivepoint Likert scale, from ${ }^{(1)}$ totally disagree up to ${ }^{(5)}$ totally agree. In Part B, which measured the evaluation that the subject made on each consequence of the valvular disease, mentioned in the first scale, the responses ranged from $^{(1)}$ very poor up to ${ }^{(5)}$ very good.

To calculate the score, each item corresponded to the product of the scores obtained in Parts A and B of the ID$\mathrm{CV}$, which may generate a minimum score of 1 and a maximum of 25 for each statement. The closer the score is to 1 , the lower the perceived impact of the subject and the closer to 25 , the greater the impact.

In Part A, items 1, 5 and 8, had their scores reversed, because they were the favorable impact perceptions, so that all assertions could be evaluated in the same direction; in Part B, the scores of all items were also reversed, with the lower the score, the better the evaluation that the patient made of the statement.

For calculation of the score, a sum of all the products obtained was performed, with a possible range of 14 up to 350 . The lower the score, the less the patient perceived the negative consequences of the disease on his life; the higher the score, the more the patient recognized the occurrence of the negative consequences of the disease on his life, and these were interpreted by him as negative ${ }^{(9)}$.

\section{Data analysis}

The data were entered into the SAS - System for Windows program (Statistical Analysis System, version 9.2, SAS Institute Inc., 2002-2008, Cary, NC, USA), for the following analyses:

- Descriptive: for measures of position (mean, median, minimum and maximum) and dispersion (standard deviation) for sociodemographic and clinical data and the IDCV scores; the acceptability of IDCV was assessed by means of the percentage of unanswered items and the proportion of patients who responded to all items ${ }^{(15)}$; the floor effect (percentage of patients who scored at floor level - equivalent to the $10 \%$ worst results on the scale); and the ceiling effect (percentage of patients who scored at the ceiling level - that corresponded to $10 \%$ best results on the scale) $)^{(16)}$ for each of the items of the IDCV, and interpreted according to the criteria previously established ${ }^{(17)}$;

- Reliability: regarding internal consistency by the Cronbach's alpha coefficient. An alpha $>0.70$ was considered satisfactory ${ }^{(18)}$. For the stability of the measure, the ICC was used, considering evidence of stability ICC $>0.70^{(13)}$.

\section{Ethical aspects}

The study was approved by the Committee on Ethics in Research (Document No. 841/2010).
Impact of the disease: acceptability, ceiling and floor effects and reliability of an instrument on heart failure Rodrigues SLL, Rodrigues RCM, São-João TM, Pavan RBB, Padilha KM, Gallani MC 


\section{RESULTS}

\section{Sociodemographic and clinical characterization}

The sample consisted of 135 patients, with a predominance of males (61.5\%), a mean age of 54.7 (11.8) years, Caucasians $(78.5 \%)$, living with a partner or family members (87.4\%), inactive (77.0\%), with 5.7 (3.9) years of education, and average family income of 3.1 (2.2) minimum wages (MW) (Table 1 ).

Table 1 - Sociodemographic and clinical characterization of outpatients with heart failure at a university hospital - Campinas, 2010-2012.

\begin{tabular}{|c|c|}
\hline \multicolumn{2}{|l|}{ Sociodemographic and Clinical Variables } \\
\hline Age (years), Mean (SD) & $54.7(11.8)$ \\
\hline \multicolumn{2}{|l|}{ Gender, \% (n) } \\
\hline Masculine & $61.5(83)$ \\
\hline \multicolumn{2}{|l|}{ Color, \% (n) } \\
\hline White & $78,5(106)$ \\
\hline \multicolumn{2}{|l|}{ Social Living Situation, \% (n) } \\
\hline With companion and/or family members & $87,4(118)$ \\
\hline Alone & $12,6(17)$ \\
\hline Education (in years), Mean (SD) & $5,7(3,9)$ \\
\hline \multicolumn{2}{|l|}{ Work Situation, \% (n) } \\
\hline Inactive & $77,0(104)$ \\
\hline Active & $15,5(21)$ \\
\hline Housewife & $7,5(10)$ \\
\hline $\begin{array}{l}\text { Family income } \\
\left.\text { (minimum wages }-\mathrm{MW}^{*}\right) \text {, Mean (SD) }\end{array}$ & $3,1(2,2)$ \\
\hline \multicolumn{2}{|l|}{ Lifestyle / Habits, \% (n) } \\
\hline Smoking (current and/or past) & $62,2(84)$ \\
\hline Alcohol consumption (current and/or past) & $35,5(48)$ \\
\hline \multicolumn{2}{|l|}{ Associated clinical conditions, \% (n) } \\
\hline Hypertension & $83,0(112)$ \\
\hline Myocardial infarction or angina & $54,0(73)$ \\
\hline Dyslipidemia & $43,0(58)$ \\
\hline Diabetes Mellitus & $26,7(36)$ \\
\hline Nephropathology & $14,8(20)$ \\
\hline Stroke & $9,60(13)$ \\
\hline \multicolumn{2}{|l|}{ Symptoms (in the last month), \% (n) } \\
\hline Fatigue & $72,6(98)$ \\
\hline Dyspnea & $65,2(88)$ \\
\hline Lower limbs edema & $51,0(69)$ \\
\hline Lipothymia & $49,6(67)$ \\
\hline Chest pain & $42,2(57)$ \\
\hline Palpitations & $42,2(57)$ \\
\hline \multicolumn{2}{|l|}{$\begin{array}{l}\text { Functional Classification - NYHA** } \\
(n=134), \%(n)\end{array}$} \\
\hline FC I & $10,4(14)$ \\
\hline FC II & $44,0(59)$ \\
\hline FC III & $35,1(47)$ \\
\hline FC IV & $10,4(14)$ \\
\hline LVEF, Mean \% (SD) $\dagger * * *$ & $48,7(16)$ \\
\hline Decreased LVEF, \% (n) $\dagger * * *$ & $68,2(83)$ \\
\hline Systolic Dysfunction, \% (n) $\uparrow * * *$ & $71,4(90)$ \\
\hline $\begin{array}{l}\text { Diastolic Dysfunction with preserved } \\
\text { LVEF, \% (n) }+* *\end{array}$ & $28,6(36)$ \\
\hline
\end{tabular}

Associated clinical conditions were: hypertension (83\%) and $\mathrm{MI}$ (54.0\%). Fatigue (72.6\%) and dyspnea $(65.2 \%)$ were the most frequently reported symptoms over the past month. The majority of patients (79.1\%) were classified in the FC-II, or FC-III, according to the NYHA. Echo Doppler cardiography data were obtained from 126 subjects, with mean LVEF observed in $48.7 \%(16)$. A large part of the individuals (68.2\%) had a reduced LVEF. Systolic dysfunction was present in $71.4 \%$ and diastolic dysfunction with preserved LVEF in $28.6 \%$ of patients.

The sociodemographic and clinical characterization data are presented in Table 1.

\section{Acceptability and ceiling and floor effects of the IDCV}

The acceptability of the IDCV in the first application (test) and in the second (retest) was of $100 \%$; that is, all the patients responded to all the items of the IDCV. An IDCV total mean of 173.1 (67.2) and a median of 172 were evidenced. Considering that for the total IDCV, the approximate value of 170 was the one that classified the subjects into categories in which low impact (total score $<170$ ) and high impact (total score $>170$ ) was perceived, the obtained values indicated an intermediate situation of impact of the disease in daily life.

Scores lower than the mean value (less impact of the disease) were observed in the domains Impact of the disease on daily activities $(61$ (27.6)) and Adaptation to the disease (10.5 (7)). Considering that the lower the score of the IDCV, the lower the impact of the disease in the one's life, a ceiling effect was observed ( $10 \%$ possible best results on the scale) when calculating the total score of the IDCV, for example, produced scores $\leq 47.6$, and the floor effect ( $10 \%$ possible worst results of the scale), when the total score was $\geq 316.4$ (Table 2).

The same calculation was applied for the domains of the IDCV and $18.5 \%$ of patients scored in the bottom $10 \%$ results of the scale in the domain - Physical impact of the disease - symptoms and $11.8 \%$ in the Social and emotional impact of the disease domain. The domain $\mathrm{Im}$ pact of disease on daily activities scored in the top $10 \%$ best results of the scale (ceiling effect), while $34.8 \%$ of the individuals also scored ceiling in the domain Adaptation to the disease (Table 2).

\section{Reliability}

The reliability of the IDCV was evaluated with regard to the homogeneity of the items, that is, the internal consistency (estimated by the Cronbach's alpha coefficient) and regarding the stability of the measure (testretest) by the ICC. 
Table 2 - Descriptive analysis and ceiling and floor effects of the instrument Impact of the Disease on the Daily Life of Patients with Valvular Disease on heart failure - Campinas, 2010-2012.

\begin{tabular}{lccccccc}
\hline \multicolumn{1}{c}{ Domain } & Mean (SD) & Median & Range & $\begin{array}{c}\text { Definition of } \\
\text { Floor Effect* }\end{array}$ & $\begin{array}{c}\text { Definition of } \\
\text { Ceiling Effect } \uparrow\end{array}$ & $\begin{array}{c}\text { Floor } \\
\text { Effect } \\
\text { (\%) }\end{array}$ & $\begin{array}{c}\text { Ceiling } \\
\text { Effect } \\
\mathbf{( \% )}\end{array}$ \\
\hline IDCV - Total score & $173,1(67,2)$ & 172,0 & $14-350$ & Escores $\geq 316,4$ & Escores $\leq 47,6$ & - & 0,7 \\
Physical impact of the disease - Symptoms & $46,3(19)$ & 49,0 & $3-75$ & Escores $\geq 67,8$ & Escores $\leq 10,2$ & 18,5 & 0,7 \\
Impact of the disease on daily activities & $61(27,6)$ & 64,0 & $5-125$ & Escores $\geq 113,0$ & Escores $\leq 17,0$ & - & 1,5 \\
Social and emotional impact of the disease & $55,5(26,6)$ & 54,0 & $4-100$ & Escores $\geq 90,4$ & Escores $\leq 13,6$ & 11,8 & 1,5 \\
Adaptation to the disease & $10,5(7)$ & 9,0 & $2-50$ & Escores $\geq 45,2$ & Escores $\leq 6,8$ & - & 34,8 \\
\hline
\end{tabular}

${ }^{*}$ Floor effect is equivalent to the $10 \%$ worst possible results of the scale; $†$ Ceiling effect is equivalent to the $10 \%$ best possible results of the scale (Bennett, 2002). Note: $(n=135)$.

Values estimated by the Cronbach's alpha were satisfactory for most of the domains, except for the domain Adaptation to the disease. In the Physical impact of disease - symptoms domain, alpha $=0.58$ was observed and a total-item score correlation of low magnitude was observed for item $12(r=0.34)$. However, the elimination of this or other items did not improve the Cronbach's alpha in the respective domain (Table 3 ).
Regarding the stability of the measure, an ICC $>0.96$ was observed, for the majority of the domains, except for Adaptation to the disease domain. Items that demonstrated lower ICC values were: Item 5 - I live well with my heart problem (ICC $=0.73$ ), followed by item $8-$ My sex life is the same as before the heart problem (ICC $=0$ 85) (Table 4).

Tabela 3 - Mean, item-total correlation and Cronbach's alpha coefficient of the Instrument Impact of the Disease on the Daily Life of Patients with Valvular Disease (IDCV) on heart failure - Campinas, 2010-2012

\begin{tabular}{|c|c|c|c|}
\hline Variable & $\begin{array}{l}\text { Item-total } \\
\text { correlation }\end{array}$ & $\begin{array}{l}\text { Cronbach's } \\
\text { Alpha }\end{array}$ & $\begin{array}{l}\text { Cronbach's Alpha } \\
\text { (if item deleted) }\end{array}$ \\
\hline Physical impact of the disease - symptoms & & 0,58 & \\
\hline Item 11. Because of the heart problem I have severe shortness of breath & 0,43 & & 0,42 \\
\hline Item 12. Because of heart problem I feel very tired & 0,35 & & 0,54 \\
\hline Item 13. Because of the heart problem I have periods of dizziness & 0,42 & & 0,48 \\
\hline Impact of the disease on daily activities & & 0,75 & \\
\hline Item 5. I live well with my heart problem & 0,34 & & 0,76 \\
\hline $\begin{array}{l}\text { Item 7. After I've had the heart problem I started to be afraid that something } \\
\text { could happen to me }\end{array}$ & 0,58 & & 0,68 \\
\hline Item 9. Because of the heart problem, I have difficulty sleeping & 0,49 & & 0,72 \\
\hline $\begin{array}{l}\text { Item } 10 . \text { Because of the heart problem, it feels very difficult to perform my } \\
\text { daily living activities }\end{array}$ & 0,54 & & 0,70 \\
\hline Item 14 . Having a problem in my heart makes me worried & 0,66 & & 0,65 \\
\hline Social and emotional impact of the disease & & $\mathbf{0 , 8 2}$ & \\
\hline Item 2 . The heart problem makes me dependent on other people & 0,60 & & 0,80 \\
\hline Item 3. The heart problem affected my ability to work as before & 0,64 & & 0,77 \\
\hline Item 4. Now I am more irritable and nervous because of the heart problem & 0,67 & & 0,76 \\
\hline Item 6. I feel very distressed, after I've had the heart problem & 0,67 & & 0,76 \\
\hline Adaptation to the disease & & $-\mathbf{0 , 1 3}$ & \\
\hline $\begin{array}{l}\text { Item 1. After I had this heart problem I began paying more attention to my } \\
\text { health }\end{array}$ & -- & & - \\
\hline Item 8. My sex life is the same as before the heart problem & -- & & - \\
\hline IDCV Total & & $\mathbf{0 , 8 7}$ & \\
\hline
\end{tabular}

Note: $(n=135)$. 
Table 4 - Intraclass correlation coefficients (ICC) and respective 95\% confidence intervals (95\% CI) of the Instrument Impact of the Disease on the Daily Life of Patients with Valvular Disease (IDCV) when applied to patients with heart failure - Campinas, $2010-2012$.

\begin{tabular}{|c|c|c|}
\hline Variable & ICC* & IC95\% $\dagger$ \\
\hline Physical impact of the disease - symptom & 0,96 & $0,94-0,97$ \\
\hline Item 11. Because of the heart problem I have severe shortness of breath & 0,90 & $0,85-0,93$ \\
\hline Item 12. Because of the heart problem I feel very tired & 0,88 & $0,82-0,92$ \\
\hline Item 13. Because of the heart problem I have periods of dizziness & 0,95 & $0,92-0,96$ \\
\hline Impact of the disease on daily activities & 0,97 & 0,96-0,98 \\
\hline Item 5 I live well with my heart problem & 0,73 & $0,62-0,82$ \\
\hline Item 7. After I 've had the heart problem I started to be afraid that something could happen to me & 0,94 & $0,92-0,96$ \\
\hline Item 9. Because of the heart problem I have difficulty sleeping & 0,93 & $0,90-0,95$ \\
\hline Item 10. Because of the heart problem, it feels very difficult to perform my daily living activities & 0,93 & 0,89-0,95 \\
\hline Item 14. Having a problem in my heart makes me worried & 0,96 & $0,94-0,97$ \\
\hline Social and emotional impact of the disease & 0,97 & 0,95-0,98 \\
\hline Item 2. The heart problem made me dependent on other people & 0,93 & $0,90-0,95$ \\
\hline Item 3 . The heart problem affected my ability to work as before. & 0,91 & $0,87-0,94$ \\
\hline Item 4. Now I am more irritable and nervous because of the heart problem. & 0,97 & $0,96-0,98$ \\
\hline Item 6. I feel very distressed, after I've had the heart problem & 0,93 & $0.90-0,96$ \\
\hline Adaptation to the disease & 0,91 & $0,87-0,94$ \\
\hline Item 1. Once I've had the heart problem, I started to pay more attention to my health & 0,97 & $0,95-0,98$ \\
\hline Item 8. My sex life is the same as before the heart problem & 0,85 & $0,78-0,90$ \\
\hline Total IDCV score & $\mathbf{0 , 9 8}$ & 0,98-0,99 \\
\hline
\end{tabular}

${ }^{*}$ Intraclass correlation coefficient; $\uparrow$ Confidence interval of $95 \%$. Note: $(n=89)$

\section{DISCUSSION}

The main findings of this study indicated the acceptability of the IDCV, as well as evidences of reliability regarding the internal consistency and the stability of the measure. Concerning the acceptability, it was shown that the IDCV was an easy to understand instrument, since the patients enrolled in the study responded to $100 \%$ of the items, a finding corroborated by a previous study ${ }^{(11)}$.

The analysis of the distribution of scores of the IDCV revealed the presence of a moderate ceiling effect (34.8\%) for the domain Adaptation to the disease, as well as a low floor effect for the domains considered substantial, Physical impact of the disease - symptoms (18.5\%) and Social and emotional impact of the disease (11.8\%), respectively ${ }^{(17)}$.

The ceiling effect occurred when the score distribution was asymmetric and was determined by the percentage of the population that scored the highest levels of the measure, harming the detection of change in health status in situations of improvement. Nevertheless, the floor effect was observed when a percentage of the individuals scores at the lowest level of the measure, which may impair the detection of change in situations of deteriorating health condition ${ }^{(16)}$.

The presence of ceiling and floor effects can influence the sensitivity and responsiveness, important psychometric properties of the instruments of measurement. Although there was no clarity in the type of change that a responsive instrument must be able to detect, that is, if clinically significant changes occur over time, changes relating to the effect of the treatment or changes in the actual value of the studied construct, the variability of the score may influence the evaluation of responsiveness of an instrument ${ }^{(19)}$.

Considering that one of the methods for evaluating the responsiveness consists of an approach based on statistical distribution, that is, measures based on the longitudinal distribution of the sample ${ }^{(20)}$, any decrease in the variability in the scores, such as floor or ceiling effects, can minimize the sensitivity for detecting differences and the responsiveness for change ${ }^{(21)}$. As the psychosocial measures such as Health-Related Quality of Life (HRQoL) and the measures of impact could be used as a primary result (outcome) in clinical trials, it is essential that their accuracy in the detection of changes over time is demonstrated ${ }^{(20)}$.

The findings of this study suggest that the IDCV presents the potential to measure clinical improvement, except for the domain Adaptation to the disease, which can have the effect of reducing, especially for the measurement of worsening, Physical impact of the disease - symptoms, and Social and emotional impact of the disease, since the ground effect was detected in these domains.

As for reliability, the findings of this study showed that the IDCV presented satisfactory evidence as to the stability of the measure. In previous studies involving the application of the IDCV in valvular pathologies ${ }^{(9)}$ and in populations with coronary artery disease ${ }^{(10-11)}$, this property of measurement was not evaluated.

With regard to the internal consistency, the Cronbach's alpha coefficient analysis showed homogeneity in the majority of the items. Correlation of low magnitude was found for item 12 pertaining to the domain Physical impact of the 
disease - symptoms, and for item 5 of the domain Adaptation to disease. However, the exclusion of these or other items did not improve the Cronbach's alpha coefficient in their respective domains. Unsatisfactory values were observed in the domain Adaptation to the disease, a finding observed in previous studies involving patients with valvular pathologies ${ }^{(9)}, \mathrm{MI}^{(10)}$ and/or angina ${ }^{(11)}$.

The lower than the acceptable Cronbach's alpha value in the domain Adaptation to the disease can be explained by the composition of this domain by only two uncorrelated items. Moreover, the construction of the Once I've had the heart problem, I started to pay more attention to my health can be interpreted in more than one way, that is, as a good or bad consequence, which points to a lack of clarity in the construction of the item. Similarly, the item My sex life is the same as before the heart problem does not enable the assessment of whether the consequence of the disease was good or bad, because the quality of sexual life of the patient before the heart disease was not known.

These findings corroborate those of previous studies in which satisfactory values were encountered for most domains and the total score of the IDCV, except for the domain Adaptation to the disease $e^{(9-11)}$.

\section{REFERENCES}

1. Roger VL, Go AS, Lloyd-Jones DM, Benjamim EJ, Berry JD, Borden WB, et al. Heart Disease and Stroke Statistics - - 2012 Update: A report from the American Heart Association. Circulation. 2012;125(1):e2-e220.

2. Margoto G, Colombo RCR, Gallani MCBJ. Clinical and psycossocial features of heart failure patients admitted for clinical decompensation. Rev Esc Enferm USP [Internet]. 2009 [cited 2012 Ago 27];43(1):44-53. Available from: http://www.scielo. $\mathrm{br} / \mathrm{pdf} /$ reeusp/v43n1/en_06.pdf

3. Moser DK, Frazier SK, Worral-Carter L, Biddle MJ, Chung M, Lee KS, et al. Symptom variability, not severity, predicts rehospitalization and mortality in patients with heart failure. Eur J Cardiovasc Nurs. 2011;10(2):124-9.

4. Bekelman D, Havranek E, Becker D, Kutner J, Peterson P, Wittstein I. Symptoms, depression, and quality of life in patients with heart failure. J Card Fail. 2007;13(8):643-8.

5. Pressler SJ, Subramanian U, Perkins SM, Gradus-Pizlo I, Kareken $D$, JinShil K, et al. Measuring depressive symptoms in heart failure: validity and reliability of the patient health questionnaire-8. Am J Crit Care. 2011;20(2):146-52.

6. Wu JR, Lennie TA, Jong MJ, Frazier SK, Heo S, Chung ML, et al. Medication adherence is a mediator of the relationship between ethnicity and event-free survival in patients with heart failure. J Card Fail. 2010;16(2):142-9.
Therefore, the findings of this study reinforce the recommendations of previous findings that tested the instrument among different populations ${ }^{(9,11)}$, which point to the need for revision of the items belonging to the domain Adaptation to the disease, and/or the exclusion of these items, which could result in a better performance of the scale, and which recommends the continuation of further research with the intent of continue testing its validity among patients with HF.

\section{CONCLUSION}

The main contribution of this study was to demonstrate the acceptable measurement properties of the IDCV in patients with $\mathrm{HF}$, although the instrument was originally created for patients with valvular disease.

Future studies among different populations of cardiovascular disease patients are suggested, as well as factorial analysis, in order to refine the measurement properties so that the IDCV can be widely used as a tool for evaluating the effect of nursing interventions aimed at reducing the impact and improving the HRQoL of patients with heart disease.

7. Tansey P. Counting the cost of heart failure to the patient, the nurse and the NHS. Br J Nurs. 2010;19(22):1396-401.

8. Scattolin FAA, Diogo MJD, Colombo RCR. Correlação entre instrumentos de qualidade de vida relacionada à saúde e independência funcional em idosos com insuficiência cardíaca. Cad Saúde Pública. 2007;26(11):2705-15.

9. Padilha KM, Gallani MCBJ, Colombo RCR. Validity of an instrument to measure the impact of valve heart disease on the patient's daily life. J Clin Nurs. 2007;16(7):1285-91.

10. Rodrigues SLL, Rodrigues RCM, Gallani MCBJ, Padilha KM. Medida do impacto da doença: validação de instrumento entre coronariopatas. Rev Soc Cardiol Estado de São Paulo. 2008;18(2 Supl B):137.

11. Santos RA, Rodrigues RC, Padilha KM, Rodrigues $S$ de $L$, Spana TM, Gallani MCBJ. Validation of an instrument to measure the impact of coronary disease on patient's daily life. J Clin Nurs. 2012;21(3-4):485-94.

12. Polit DF, Beck CT, Hungler BP. Fundamentos de pesquisa em enfermagem: métodos, avalição e utilização. 5a ed. Porto Alegre: Artes Médicas; 2004.

13. Streiner DL, Norman GR. Health measurement scales: a practical guide to their development and use. 3th ed. New York: Oxford University Press; 2003.
Impact of the disease: acceptability, ceiling and floor effects and reliability of an instrument on heart failure Rodrigues SLL, Rodrigues RCM, São-João TM, Pavan RBB, Padilha KM, Gallani MC 
14. Bocchi EA, Braga FGM, Ferreira SMA, Rohde LEP, Oliveira WA, Almeida DR, et al. III Diretriz Brasileira de Insuficiência Cardíaca Crônica 2009. Arq Bras Cardiol. 2009;93(1 Supl.1):1-71.

15. Netherlands Cancer Institute, Amsterdam. Assessing health status and quality-of-life instruments: attributes and review criteria. Qual Life Res. 2002;11(3):193-205.

16. Bennett SJ, Oldridge NB, Eckert GJ, Embree JL, Browning $\mathrm{S}$, Hou $\mathrm{N}$, et al. Discriminant properties of commonly used quality of life measures in heart failure. Qual Life Res. 2002;11(4):349-59.

17. McHorney CA, Ware JE, Lu JFR, Sherbourne CD. The MOS 36-item Short-Form Health Survey (SF-36): III. Tests of data quality, scaling assumptions and reliability across diverse patient groups. Med Care. 1994;32(1):40-66.
18. Cronbach LJ. Coefficient alpha and the internal structure of tests. Psychometrika. 1951;16(3):297-334.

19. Oliveira AS, Santos VLCG. Responsividade dos instrumentos de avaliação de qualidade de vida de Ferrans \& Powers: uma revisão bibliográfica. Acta Paul Enferm. 2011;24(6):839-44.

20. Eurich DT, Johnson JA, Reid KJ, Spertus JA. Assessing responsiveness of generic and specific health related quality of life measures in heart failure. Health Qual Life Outcomes. 2006;4:89.

21. Riegel B, Moser DK, Glaser D, Carlson B, Deaton C, Armola R, et al. The Minnesota Living With Heart Failure Questionnaire: sensitivity to differences and responsiveness to intervention intensity in a clinical population. Nurs Res. 2002;51(4):209-18. 